\title{
The Writing Series Project: A model for supporting social work clinicians in health settings to disseminate practice knowledge
}

Social work practitioners working across healthcare settings deliver innovative services in their daily work that benefit patients and their families. These social workers are uniquely positioned to disseminate valuable practice experience and engage in interdisciplinary collaboration, thus contributing to knowledge development within their field of practice and across disciplines. This knowledge dissemination can enhance service delivery and patient care outcomes, as practitioners engage in a dialogue that ensures they critically reflect on their practice and keep up to date with research in their field. Given the wealth of experiences practitioners go through in their daily work, they have much to contribute to social work's knowledge base (Staudt, 2003). Not only do practitioner's regularly implement innovative initiatives, they are continually moulding theory to practice and practice to theory. The lessons learned from these processes would help others in their practice. Thus, writing for publication would allow practitioners to share their practice knowledge, ideas, reflections, and discoveries. Engagement in writing, and ultimately research, contributes to the 'safety' of the profession, particularly in contested spaces such as health (Beddoe, 2011).Thus, social workers must expand their skill set beyond clinical work to ensure their viability in practice. Further, social workers often rely on methods of practice and research findings from other disciplines. This is valuable, but to strengthen social worker's professional identity and the standing of the profession more widely, social workers need also to be contributing expertise to such knowledge generation, with the ultimate aim of improving patient care outcomes.

Regrettably however, practitioner expertise is seldom disseminated publicly through peer-reviewed journals, papers at professional meetings, or empirical practice-based research (Judd \& Sheffield, 2010; Sidell, et al., 1996). Such activities tend to be dominated by academic scholars, who may overlook valuable clinical information or view it as unreliable 
(Epstein, 2001). Without greater involvement from practitioners, quality social work research may become narrowly defined (Heron \& Murray, 2004).

Over the last twenty-five years, social work editors have attempted to entice practitioners to publish in their journals. Williams and Hopps $(1987,1988)$ reported that the editorial board of their journal, Social Work, had undertaken to outreach to practitioners to publish. In support of this endeavour, they published tips for potential authors on how to structure a manuscript $(1987 ;$ 1988). In 1991, Pruet, Shea, Zimmerman, and Parish in Social Work in Health Care reported on a collaborative model promoting joint research between academics and practitioners; while Adler et al. (1993) described the successes and challenges of two research-writing groups. Later that decade, Families in Society featured a letter from Andrew Malekoff (1999) so that the reader could "learn about the personal inspirations and influences that compel people to write" (p. 190). In 2003, Naiburg presented her findings from interviews with twelve editors of clinical practice journals for potential authors, which illuminated the process of journal submission, review, and acceptance; while others provided tips to journal editors on how to strengthen their journal, which included the suggestion of recruiting articles from diverse fields of social work practice that use diverse research methods (Marsh, 2005).

Similarly, a number of texts exist in social work that promote practitioner writing and research. For example, in his recent text, Esptein (2010) describes a 'clinical-data mining' approach to integrating practice and research, where he encourages practitioners - as well as academics - to analyse agency records to not only build knowledge and enhance practiceinformed research, but also to contribute to practitioner decision making and reflection. Meanwhile Thyer (2008) and Healy and Mulholland (2007) focus on demystifying writing skills for social workers, with Thyer focusing on writing and publishing peer reviewed journal articles, and Healy and Mulholland focusing on writing skills more broadly. 
Numerous authors have also shared their tips for navigating the publication process in peer reviewed journal articles (see Bender \& Windsor, 2010; Malekoff, 2006; Steinberg, 2007). For example, Bender and Windsor (2010), identified four Ps to publishing - personal, people, publishers, and productivity - where they encouraged postdoctoral students to explore personal barriers to publishing, collaborate with academics and other doctoral students, select appropriate journals, and allocate productive time for writing; and more recently Luiselli (2010) encouraged human service professionals to write with the guide of a performance enhancement plan. Interestingly, our colleagues in medicine (Sridhar, et al., 2011; Vintzileous \& Ananth, 2010) and nursing (Bragadóttir, 1998; Carlson, 2010; Lannon, 2007; Northam, Yarbrough, Haas, \& Duke, 2010; Rolfe, 2009; Wachs, Williamson, Moore, Roy, \& Childre, 2010) face similar challenges in supporting practitioners' writing. Despite ongoing efforts of editorial boards and authors to promote practitioner publication, there still exists a greater need for practitioner involvement and contribution to research and writing.

Collaborative endeavours between practitioners and academic researchers provide one pathway towards the dissemination of practice knowledge (Berg-Weger, et al., 2005; Fisher, Fabricant, \& Simmons, 2005; Galinsky, Turnbull, Meglin, \& Wilner, 1993; Hess \& Mullen, 1995; Macduff \& Netting, 2000; Staudt, Dulmus, \& Bennett, 2003). This can take the form of a writing group. Writing groups increase participants' enthusiasm and motivation for scholarly endeavours (Ferguson, 2009; Houfek, et al., 2010; Parker, 2009), improve writing skills, and enhance confidence (Cuthbert \& Spark, 2008; Parker, 2009; Rickard, et al., 2009). Such groups motivate members as they become accountable to the group. Writing groups have the potential to develop collegial relationships and team building amongst colleagues (Jackson, 2009). Participants benefit from peer critique and peer review of their work (Parker, 2009; Rickard, et al., 2009) and such groups have been associated with increased publication output of group members to peer-reviewed journals (Jackson, 2009). 
To date, only two articles on writing groups for social workers could be located (Adler, et al., 1993; Fouché \& Lunt, 2009), however, two others describe similar initiatives that provided training and support for empirical research projects with social workers in the UK (Powell, \& Orme, 2011; Shaw \& Lunt, 2011). These groups experienced a number of challenges. Some of these related to the group process and group members' competing work priorities (Fouché \& Lunt, 2009). Employers generally did not allow time within the workday for group members to engage in research and writing, and workloads were not adjusted according to group members' involvement in the group (Adler, et al., 1993; Fouché \& Lunt, 2009). When work time was allotted - supported by grant funding - employees were also expected to match work hours with their own personal time (Shaw \& Lunt, 2011). Practical support related to accessing literature and ethics applications was limited (Fouché \& Lunt, 2009). This was compounded, in Fouché and Lunt's (2009) study, by misunderstandings about the role of research mentoring and the group mentoring process. However, both Fouché and Lunt (2009) and Adler et al. (1993) found that their groups had benefits. For Adler et al. (1993) practitioners' publication rates increased; and for Fouché and Lunt (2009) practitioners learned about the research process, developed professionally through exposure to research projects, and were able to make more informed decisions about research and practice. Academics developed networks with practitioners and gained access to practice data. There was also enhanced communication amongst practitioners within and across organizations, as well as constructive changes to service delivery and data collection (Fouché \& Lunt, 2009). Similarly, writing groups have been successful in other areas, including academic faculty (Berger, 1990; Green \& Baskind, 2007; Grzybowski, et al., 2003; Rickard, et al., 2009) doctoral students (Bender \& Windsor, 2010), and nurses (Shatzer, et al., 2010; Stone, LevettJones, Harris, \& Sinclair, 2010).

Unfortunately, social workers tend to shy away from research and writing (Judd \& Sheffield, 2010; Sidell, et al., 1996), a process that would help them remain critically 
reflective in their practice. Thus, it is important that practitioners are better supported in scholarly endeavours so that they are leaders in critically reflective practice and their expertise becomes a more explicit component of the knowledge generation process, with the ultimate aim of improving patient care outcomes. Given the success of documented writing groups and the importance of collaboration between academics and the field, a writing group was trialled with social workers in the Gold Coast Health Service District in southeast Queensland, Australia, which commenced in March 2009.

Our Writing Series Project, presented here, aims to (i) equip practitioners with knowledge and strategies for writing for peer-reviewed scholarly journals, conferences, and grant applications, (ii) encourage practitioners to be competent, confident writers, (iii) support reflective practice, (iv) provide academic consultation regarding idea formulation and development, (v) enhance collaborative writing and research endeavours between academics and practitioners, (vi) raise the profile of social work in health settings, and (vii) create a culture where professional writing and presenting are valued. The project seeks to promote the dissemination of social work practice knowledge to a wide audience, thereby improving service delivery and client outcomes. Ultimately, we wish to help social workers contribute to knowledge in the field, improve client outcomes, and solidify our importance, in health settings.

\section{The Writing Series Project: The impetus for program development}

The Gold Coast Health Service District spans a large geographical area of approximately $1400 \mathrm{~km}^{2}$. The district is a major tourist destination, characterised by extreme opulence alongside severe socioeconomic disadvantage, a large transient population, and a high number of frail aged people, many of whom have retired away from social supports and family. The Gold Coast has a rapidly expanding population and is currently the sixth largest city in Australia. This has resulted in increasing demands on health services. At present, there 
are approximately 95 social workers employed by the Gold Coast Health Service District across the continuum of healthcare including acute, sub acute, community, and mental health.

Whilst the social workers are engaged in developing and delivering unique programs, they have historically had very low levels of engagement in research and dissemination of their work through presentations and publications. This is partly attributable to the lack of non-clinical time for social work clinicians. For example, historically, social work staffing levels have only factored in direct patient care so that the productivity of one full time equivalent social worker was expected to be nearly $100 \%$ clinical. There was little time built in to the staffing establishment for the required administrative and non-clinical duties, let alone for writing, research, and teaching. This is compounded by a limited number of computers and practitioners experiencing difficulties accessing the internet while at work. In contrast, colleagues in nursing and medicine, for many years, have had recognised clinical teaching and scholarly responsibilities and these duties are supported by an array of clinical educators and research assistants. This situation is not unique to the Gold Coast Health Service District; it is a common scenario for social workers in health and mental health internationally. Yet social workers in health and mental health are increasingly required by their employers to publish and undertake research.

Requirements to engage in writing, teaching, and research are increasingly being included in allied health (for example, social work and physiotherapy) role descriptions in the Gold Coast Health Service District. The health service vision is to be the "the greatest provider of public healthcare services in Australia" and it is currently involved in the largest public health infrastructure program in the country, building the Gold Coast University Hospital, which is scheduled to open in late 2012 adjacent to Griffith University. The increasing expectations regarding research participation, clinical teaching involvement, scholarly writing, and completion of higher education degrees creates challenges for practitioners with $100 \%$ clinical loads as they attempt to juggle competing responsibilities, 
and their team leaders attempt to support them in their non-clinical duties. It might be expected that such changes in expectations could be met with resistance. The introduction of a new industrial agreement in late 2007 saw increased incentives for health social workers to engage in scholarly activities with improved career structures and higher degree allowances. These incentives are important, because as Yaeger (2008) suggests "operators of the system whose work routines will be impacted by the change must perceive payoffs that will motivate them to learn and use the new system and not sabotage it" (p. 15).

Amodeo, Ellis, Hopwood, and Derman (2007) note that to solidify organizational change practitioners need to be supported through various training. Thus, to move from a starting point of low levels of presentations and publications within a group of social workers to a position where such activities are viewed as a core part of a clinician's role requires a significant shift in practitioners' confidence in their abilities, coupled with significant training. Whilst for new graduates, writing skills might be more recently practised, social workers who have been away from tertiary study for some years often lack currency of knowledge of the conventions and strategies for getting their work published or accepted for presentation. In order to become competent and confident writers, social work practitioners needed tailored training.

The introduction of the Master of Social Work program offered by Griffith University School of Human Services and Social Work to the Gold Coast Campus early in 2009 provided unique opportunities for health and mental health social workers to begin partnering with academics in research, writing, teaching, and practice. The arrival of a visiting professor of social work (third author), undertaking sabbatical at Griffith University and spending time in the hospital, added impetus. Consequently, we, the authors and group facilitators, launched our writing group project in March 2009 for health and mental health social work clinicians. 


\section{The Writing Series Project: Theoretical and procedural aspects}

\section{Theoretical framework}

The theory of social group work, where participants with common interests convene to share information and engage in purposeful activities (Barker, 2003), informed the writing group development. We believed that group work would be beneficial to the practitioners as it would provide opportunities to uncover practitioner strengths, thus increasing their confidence in writing. The group would provide opportunities for practitioners to learn new things and practise new ways of being with an audience to motivate and applaud. It would enhance their opportunities to share their knowledge and skills. Practitioners would gain a sense of belonging when they attended and this could lead to writing support networks existing outside of the group. The active involvement of practitioners would also make them more likely to take ownership of, and responsibility for, their contributions and roles (Hoover, 2005). We believed that group exercises would have immediate application to their writing endeavours and more broadly to their professional relationships, while at the same time, appealing to their diverse learning styles and life experiences.

Group work was underpinned by a social constructivist view of knowledge acquisition, which posits that all knowledge is socially constructed through human interactions and is influenced by the social aspects of a person's environment, such as culture, history, and politics (Houston, 2001). From this constructivist perspective, we recognised that practitioners had valuable experiences that would affect how they constructed new knowledge from the learning experienced in the group. We also appreciated that through interactions with each other and the environment in which they worked, the practitioners would actively construct new understandings about their experiences and learning (Gray, 2001). We believed that practitioners would construct or co-construct knowledge through actively engaging in the group processes and experiential learning exercises. As a result, practitioners were invited to reflect on their experiences within the group to identify how they might apply their new 
learning to their workplace and other situations. However, we recognised that changes in writing behaviour would not be solely determined by the introduction of new material or personal reflection. Rather, it required critical exploration of existing knowledge, as well as a place to build theory, test action, and reflect on experience (Johnson \& Johnson, 2006) and, consequently, we sought to make this possible.

This writing group was also informed by a pragmatic approach to evidence-based practice; that is, an approach which is inclusive of all forms of evidence and takes a critically reflective stance to the evaluation of that evidence. It is an approach which, recognising the constraints of practice, embraces practice wisdom and all forms of empirical research. It acknowledges the importance of considering contextual factors when making practice decisions. It also promotes practice-based research and the synthesis and critical evaluation of all research (Gray, Plath, \& Webb, 2009; Plath, 2006; see also Epstein, 2009; Gilgun, 2005; Marks, 2002; Nevo \& Slonim-Nevo, 2011; van de Luitgaarden, 2009; Zayas, Drake, \& Jonson-Reid, 2010). This approach enabled us to draw on a range of evidence to promote writing, including qualitative and descriptive journal articles, previous experience, and knowledge of other practice models. Moreover, it is consistent with the two broad and longstanding functions of professional social work journals, namely the building of knowledge and the exchange of practitioners" "experiences, insights and innovations" (Else, 1978, p. 270).

We also decided that this approach is important because healthcare social workers, in particular, are "resident guests" within a "host organization" (Dane \& Simon, 1991); that is, they work in organizations whose purpose and decision making are defined by professionals who are not social workers. As a result, "The responsibility lies with social work to evolve and align with the changing face of our hosts" (Silverman, 2008, p. 89). Social workers are increasingly viewed as integral members of the healthcare team, but their positions within the organization remain vulnerable. They need to safeguard their continued existence for the sake 
of the patients they provide services to. In part, this can be achieved by engaging in scholarly endeavours.

\section{Procedure}

We were guided by the scholarly literature on writing groups in designing the format of the group. For example, we encouraged attendees to seek outside mentoring to help them with their writing and in some instances we paired a practitioner with an academic. This is because writing groups are enhanced by mentoring that operates alongside the group and incorporates role-modelling, coaching, and counselling (Tariman, 2009; Zellars, Howards, \& Barcie, 2008). Social workers were strongly encouraged to attend the launch of the Writing Series Project introductory workshop, which was held as a district-wide continuing education activity attended by 45 social workers. However, group attendance was voluntary, as writing groups should comprise of voluntary participants (Ferguson, 2009) who provide mutual mentorship and reciprocity (Fouché \& Lunt, 2009; Houfek, et al., 2010; Lee \& Boud, 2003). In line with Hislop, Murray, and Newton (2008), we provided a space for practitioners to develop writing support networks and overcome barriers to writing. Step by step instructions on how to write for publication and in-class writing activities were provided, as this has been shown to demystify the writing process (Cuthbert \& Spark, 2008; Fouché \& Lunt, 2009; McCleary, 2008). It is also important that group members have the opportunity to have their work critiqued as well as critique the work of others (Aitchison, 2009), and are provided with opportunities to adopt new writing behaviours (Hislop, et al., 2008). Thus, exercises in the group were designed to facilitate this process.

The writing groups were predominantly small (maximum fifteen attendees). This is important because small group size is useful in developing rapport and trust (Ferguson, 2009). Further, writing groups should provide members with opportunities to interact with their peers and problem-solve writing challenges together (Ferguson, 2009; Houfek, et al., 2010). 
Discussion of, and agreement on, group structure, process, and methods, and group process guidelines is useful (Houfek, et al., 2010) and our practitioners were encouraged to set optimistic and realistic goals (McCleary, 2008). Successful writing groups are reliant on commitment from group facilitators and a workplace culture which views writing and researching as 'normal business' (Lee \& Boud, 2003).

Since starting, we have had seven workshops. On average, ten practitioners attended each group. Practitioners have been encouraged to meet in small groups between workshops and the third author, a visiting professor from the United States, provided individual mentoring. Workshops have focused on (i) getting started with writing, (ii) navigating the conference presentation process, (iii) searching for literature, (iv) converting literature into a review, (v) creating a poster presentation, (vi) writing an abstract, and (vii) strategies for staying up-to-date with the latest research, theory and practice developments. Future workshop topics are determined in consultation with social work practitioners and will likely cover content such as choosing titles, preparing a journal article, and journal selection. Selected sample exercises from the program are described in Table 1.

As the facilitators of the writing group, we met between each workshop to critically reflect on the workshop and we adapted the program format according to this reflection. In recognition of the realities and constraints of practice, and in line with a pragmatic approach to evidence-based practice, we also attempted to develop practitioner skills and knowledge in searching for and reviewing literature not limited to meta-analyses, randomised control trials, and other methods valued in the evidence based practice knowledge hierarchy. Through the workshops we sought to support and train practitioners in the effective use of research findings, promote knowledge of, and basic skills in, practice based research, and help practitioners develop an ability to synthesise and critically evaluate research. 


\section{Summary of program outcomes}

Despite the merits of our writing group project, we recognise that this descriptive article is limited, such that, as a next step, future research is warranted to systematically evaluate our writing series in order to establish outcomes data and empirically-based effective writing group practices. Nevertheless, our trial project provided good preliminary data and lessons learned for the future. Our experience highlights the organisational constraints that other groups could anticipate arising and we offer suggestions for overcoming these. It also offers a strong theoretical foundation on which other groups could base such an initiative. To date, no such theoretical framework has been put forward for a social work writing group and there has been little social work commentary on specific teaching methods and program content in social work writing groups (for exceptions, see Adler, et al., 1993; Fouché \& Lunt, 2009). Here we report on the tangible scholarly outcomes realised, programmatic challenges, and practitioner feedback to date that offer insight into the benefits and pitfalls that we encountered.

\section{Scholarly ouatput}

Group members have had a number of scholarly activity achievements as of the writing of this article as shown in Table 2. Some of the tangible outcomes to date include a successful collaborative grant application jointly funded by Griffith University and Queensland Health to undertake research into advance directives (item 1) and a subsequent peer-reviewed journal article submitted for publication, which is currently under review (item 2). There have also been abstracts submitted to two peer-reviewed international conferences (items 3 \& 4), three peer-reviewed national conferences (items 5, 6, \& 7) and one peerreviewed local conference (item 8). These abstracts were ultimately accepted and five papers were subsequently presented. The authors have also been invited to present findings from the Writing Series Project to their Victorian counterparts (item 9). A number of district social 
workers have expressed interest in undertaking a research advanced degree, including one development of a research proposal and subsequent application and enrolment to complete a Master of Philosophy (item 10). Further, a group of practitioners have been mentored by the first named author to develop a research proposal and commence the study (item 11).

A number of less tangible productivity outcomes have also been realised. The first and third authors have mentored clinicians on idea development. For example, they have mentored the second author, who is the director of social work in the health service district, in writing for publication, developing a research proposal for a research advance degree (described above), and they have co-authored conference papers together (described in Table 2). Further, they have supported the second author's application, which was successful, to become an adjunct senior lecturer with the University. Exposing practitioners to opportunities at the university via the writing group workshops and development of mentoring connections with academics has enhanced networks between the university and the health service, thus improving the integration of theory, research, and practice. It has also resulted in increased opportunities for healthcare practitioners to participate in panels on topics of interest to students, such as practice frameworks, practice experiences, preparing for job interviews, organisational structures, and so on. Three practitioners have also been involved in coteaching at the university with the first named author.

A number of these outcomes were included in an annual report of highlights for the profession which was circulated across the health service including to the Chief Executive Officer and Executive Directors of clinical divisions - an opportunity to raise the profile of social work and awareness of the more scientific endeavours of the profession. While we recognise the importance of engaging practitioners also in empirical research, it has been our strategy to first assist practitioners to learn basic skills in research-related activities and writing. We anticipate that as communication networks between the University and health 
social workers continue to grow, the project will likely result in greater research and publication output.

\section{Overcoming programmatic challenges}

We experienced a number of challenges in implementing the writing group series, consistent with the existing literature (Fouché \& Lunt, 2009), which we have endeavoured to overcome. For example, the social work departments within the Health Service District and the University have absorbed the costs of the program, because, to date, no specific funds have been allocated to support the writing group. This is problematic, particularly when pressure exists within universities for academics to gain external funding and the Health Service District is fast calling for more scholarship as part of a wider organizational cultural shift yet budgets for professional development have not always kept up with these changing expectations. However, this collaboration and provision of in-kind funds has allowed the authors to establish a valuable, productive writing group.

In recognition of how little non-clinical time social work practitioners have, preparatory requirements for each workshop were reduced. This has been important because caseloads of direct practice clinical positions in hospital, for example, have meant that social workers rarely have additional time to incorporate scholarly activities in their daily work; and it can be difficult to get release time from regular duties to attend the writing group. Ironically, even as we write, our second author, a hospital social work director, who advocates for practitioners to undertake scholarly endeavours, is challenged by the constraints of a clinical environment which mean that she is often unable to work on scholarly pursuits during work time. Additionally, social work managers have supported social work practitioner attendance at activities such as the writing group, and expectations regarding evidence based practice and increased participation in scholarly activities are increasingly being written in to performance and development plans across the social work service. Activities such as the 
writing group can be linked to organisational goals and therefore included as actions in staff learning and development plans. Social workers who have been engaged in producing abstracts or developing proposals have been released where possible from clinical responsibilities for brief periods to allow them to focus on that activity. As this has to be done within existing staffing levels, it has relied on the use of internal cover of clinical load by another social work practitioner.

Other challenges we have overcome related to marketing and how we have promoted the writing group. For example, at one point, some practitioners said they thought it was not open to new membership and because they had missed the first introductory workshop they did not think they could attend subsequent groups. Consequently, we needed to more clearly convey the purpose and content of the group and highlight the benefits of attending. We have also had a number of practical issues to address. For example, we have not always had access to a central venue given the size of the Gold Coast region. However, we have found that holding workshops at the University has increased attendance, which may be because practitioners are required to register to attend these workshops, so they are not easily distracted by other work commitments, and the University venue may hold more prestige.

\section{Practitioner feedback}

Feedback from practitioners was sought through evaluative minute papers; that is, a process where participants are asked to respond to two or three evaluative questions anonymously on a piece of paper at the conclusion of a group. This process suggested that the writing group success has been dependent on a number of factors. Practitioners have valued networking, meeting, and talking with colleagues. The writing group helped demystify the writing process for some practitioners, while others have appreciated having opportunities to receive peer critique and peer support. Practitioners also valued the experiential and interactive structure of the workshops, with some commenting on the usefulness of the 
introduction of new materials and knowledge. The primary weakness of the group, that has been consistent across feedback, is related to insufficient time allowed by the facilitators for the workshops. Practitioners have felt that more time is needed to cover each topic indepth and apply new learning. Although future program evaluation will comprise use of standardised instruments to evaluate the efficacy of the writing group, our aim here was to gain a snapshot. Written feedback provided some preliminary indication of the elements which have been most useful to the program overall. Practitioners in each of these workshops were asked to comment on what they (i) liked about the workshop, (ii) thought could be done differently, and (iii) would like included in future workshops. The key themes are as follows:

\section{Talking with colleagues and networking}

There was overwhelming feedback from practitioners in the first workshop about the value that practitioners found in talking and meeting with their colleagues, generating ideas and receiving peer support. This idea is consistent with the literature which suggests that writing groups help develop collegial relationships and team building amongst colleagues (Jackson, 2009). For example, some practitioners commented on the value of meeting colleagues: "[It was] great to network with peers, many I had not met before"; and another said, "[I liked] connecting with peers". Others valued the opportunities to discuss and generate ideas: [I liked] small group brainstorming and sharing of experiences" and "[It was] helpful to listen to other people and their ideas and views on writing". While some practitioners appreciated having time to talk with colleagues about writing: "[I liked] devoting the time to thinking about writing and talking to others about writing".

Consequently, we sought to ensure that all subsequent workshops included opportunities for networking and discussion. It is interesting to note that subsequent workshop feedback focused more on other elements, such as the experiential teaching methods used, rather than the importance of networking and seeking peer support. This could be because practitioners found particular value in this in the first workshop and the need reduced in 
subsequent workshops, or perhaps because of the large number that attended the first workshop.

\section{Demystifying and encouraging}

Practitioners found the first workshop encouraging and commented how the process had begun to demystify the process of writing. One participant said, "[The workshop] empowered me to ask for other people to assist in presenting / writing a journal or presentation," while another appreciated "knowing there is support to further ideas is a motivation". This is important, as some participants acknowledged fear and isolation in writing endeavours: "I thought I was the only one" and another "[I liked gaining] ideas on how to free write and acknowledge my fears".

Such comments were not repeated in later workshops. This could be because those who attended subsequent workshops had attended the first workshop and it was this workshop that most demystified the process for them. Further, the large number of attendees at the first workshop would have validated practitioners' fears and experiences more so than subsequent workshops where there were lower numbers.

\section{Experiential and interactive}

It is interesting to note that many practitioners reported that they enjoyed the interactive and experiential nature of the group. One practitioner echoed the sentiment of others: "[I liked] breaking into small groups to discuss ideas about writing for specific purposes." And others reported, "I thoroughly enjoyed the free writing [exercise], and "[I] loved the interactive aspect of having time to practice on the computer." Discussion of the efficacy of particular teaching methods has not previously been identified in the literature; future research on the pedagogical aspect of writing groups is needed. We, the facilitators of the writing group, have sought to ensure that each of the workshops is experiential and interactive and feedback from workshops has regularly indicated that practitioners have valued this. 


\section{Input, information, and mentoring}

It was important to not rely solely on the value of experiential and interactive learning, but recognise that learning also requires input and information from the facilitators both within and outside the group. This point, although only commented on by a small proportion of practitioners, appeared to be appreciated across most of the workshops (and particularly the later ones). For example, some practitioners stated: "[I valued] having your input briefly about what works well in posters", "the information was very useful; easy to understand and follow" and "[I valued having] access to new resources which I didn't know existed". When insufficient information was provided, one participant commented "I wished we'd had a simpletons guide to what the buttons do on this". Comments such as these highlight the importance of introducing new materials, resources, and information in workshops and not overly relying on interactive activities.

Additionally, all scholarly achievements, as described in Table 2, involved mentoring outside the workshops by either the first or third author. This suggests that while workshops are useful in providing opportunities for practitioners to practice the lessons learned, supportive one-to-one or group mentoring is also needed. In these instances, writing group members contacted the first or third author requesting input and assistance. The academic consultant guided the practitioners by teaching, modelling and explaining the nuances of the writing and research process, whether it be writing an abstract, preparing a conference presentation, formulating a research question, or something else. While the experiential, interactive nature of the workshops were useful (as described above), mentoring outside of the workshops resulted in a number of scholarly achievements.

\section{Timing}

Time was repeatedly raised as an issue within the groups. Each workshop went for approximately two hours. While all the material was covered, and it was reportedly "well paced", practitioners stated that there was not enough time to develop a full understanding of 
the topic or have enough time to practice new learning. For example, one practitioner said in the first workshop: "Time - I really didn't discover how to write a paper ". This may mean we need to set more realistic expectations regarding the writing process; however, other practitioners also felt too much was covered in too little time: "probably tried to do a bit much with the time we had". One practitioner felt distracted because of time pressures in his or her workplace: "[I did not like] not being able to fully concentrate on what was being said because I am busy and kept thinking about what I had to do". Practitioners asked for more time to practice new skills within the workshop. For example, one person said, "I need more time to practice accessing information" and another "[I would like] more time to play [on the computers] - step by step guidance". Practitioners wanted more time to digest information, as one practitioner said "perhaps we need a separate session on this ... as [I'm] greedy for more indepth [information] once the basics are there". Given the importance of allowing time for practitioners to reflect on and construct knowledge through the group process, such feedback is important. While endeavouring to balance the demands of practitioners' workplaces there is also a clear need to allocate ample time to writing workshops.

\section{Concluding Remarks}

Preliminary evidence suggests that writing groups, which are interactive, encouraging, and experiential, have considerable relevance for health and mental health social workers who wish to enhance their clinical skills and knowledge, and disseminate their knowledge within lay, clinical, and academic arenas. Given the trend in Australia, and internationally, toward evidence-based practice - and an organizational expectation in health services that clinicians will engage in scholarly activities - partnerships between universities and agencies are important. Partnerships can bring together the research skills of academics with the clinical expertise of healthcare professionals. It is evident from our experience, and existing literature, that there are considerable organizational obstacles that prevent practitioners from engaging in 
research and writing, requiring social work administrators to use creative and strategic skills to address these barriers and successfully navigate complex healthcare systems. Writing groups can assist practitioners to reflect on and improve their practice, which will not only contribute to their professional development, but it will also enhance the work they do with patients. Moreover, in healthcare arenas in which medicine and nursing research activities predominate, dissemination of social work knowledge is vital and can enhance professional credibility, visibility, and pride. 


\section{References}

Adler, G., Alfs, D., Greeman, M., Manske, J., McClellan, T., O'Brien, N., et al. (1993). Social work practitioners as researchers: Is it possible? Social Work in Health Care, 19(2), 115-127.

Aitchison, C. (2009). Writing groups for doctoral education. Studies in Higher Education, 34(8), 905-916. doi: 10.1080/03075070902785580

Amodeo, M., Ellis, M. A., Hopwood, J., \& Derman, L. (2007). A model for organizational change: Using an employee-driven, multilevel intervention in a substance abuse agency. Families in Society: The Journal of Contemporary Human Services, 88(2), 223-232. doi: 10.1606/1044-3894.3620

Barker, R. L. (2003). The social work dictionary (5th ed.). Washington, DC: NASW Press.

Beddoe, L. (2011). Investing in the future: Social workers talk about research. British Journal of Social Work, 41(3), 557-575.

Bender, K., \& Windsor, L. C. (2010). The four Ps of publishing: Demystifying publishing in peer-reviewed journals for social work doctoral students. Journal of Teaching in Social Work, 30(2), 147-158. doi: 10.1080/08841231003697999

Berg-Weger, M., Tebb, S. S., Cook, C. L., Gallagher, M. B., Flory, B., \& Cruce, A. (2005). The collaborative research education partnership: Community, faculty, and student partnerships in practice evaluation. Journal of Community Practice, 12(3), 141-162. doi: 10.1300/J125v12n03_09

Berger, R. (1990). Getting published: A mentoring program for social work faculty. Social Work, 35(1), 69. doi: 10.1007/BF00757204

Bragadóttir, H. (1998). Every nurse can be an author: On writing for publication. Nursing Forum, 33(4), 29-32.

Carlson, K. (2010). Writing: Facing the blank page. Journal of PeriAnesthesia Nursing, 25(3), 179-184. doi: 10.1016/j.jopan.2010.03.003

Cuthbert, D., \& Spark, C. (2008). Getting a GRiP: Examining the outcomes of a pilot program to support graduate research students in writing for publication. Studies in Higher Education, 33(1), 77-88. doi: 10.1080/03075070701794841

Dane, B. O., \& Simon, B. L. (1991). Resident guests: Social workers in host settings. Social Work, 36(3), 208-213.

Else, J. F. (1978). Social work journals: Purposes and trends. Social Work, 23, 267-273. 
Epstein, I. (2001). Using available clinical information in practice-based research: Mining for silver while dreaming of gold. In I. Epstein \& S. Blumenfield (Eds.), Clinical datamining in practice-based research: Social work in hospital settings (pp. 15-32). Binghamton, NY: Haworth Press Inc.

Epstein, I. (2009). Promoting harmony where there is commonly conflict: Evidence-informed practice as an integrative strategy. Social Work in Health Care, 48(3), 216-231.

Epstein, I. (2010). Clinical data-mining: Integrating practice and research. New York: Oxford University Press.

Ferguson, T. (2009). The 'write' skills and more: A thesis writing group for doctoral students. Journal of Geography in Higher Education, 33(2), 285-297. doi: $10.1080 / 03098260902734968$

Fisher, R., Fabricant, M., \& Simmons, L. (2005). Understanding contemporary universitycommunity connections. Journal of Community Practice, 12(3), 13-34. doi: 10.1300/J125v12n03_02

Fouché, C., \& Lunt, N. (2009). Using groups to advance social work practice-based research. Social Work With Groups, 32(1), 47-63. doi: 10.1080/01609510802314659

Galinsky, M. J., Turnbull, J. E., Meglin, D. E., \& Wilner, M. E. (1993). Confronting the reality of collaborative practice research: Issues of practice, design, measurement and team development. Social Work, 38(4), 440-449.

Gilgun, J. F. (2005). The four cornerstones of evidence-based practice in social work. Research on Social Work Practice, 15(1), 52-61. doi: 10.1177/1049731504269581

Gray, M. (2001). Theoretical underpinnings of the Newcastle model: Constructivism and the strengths perspective. Retrieved August, 2006, from http://www.newcastle.edu.au/school/hss/about/experiencedbasedlearning.html

Gray, M., Plath, D., \& Webb, S. A. (2009). Evidence-based practice: A critical stance. London, Routledge.

Green, R. G., \& Baskind, F. R. (2007). The second decade of the faculty publication project: Journal article publications and the importance of faculty scholarship. Journal of Social Work Education, 43(2), 281-296.

Grzybowski, S. C. W., Bates, J., Calam, B., Alred, J., Martin, R. E., Andrew, R., et al. (2003). A physician peer support writing group. Family Medicine, 35(3), 195-201.

Healy, K. \& Mulholland, J. (2007). Writing skills for social workers. London, UK: Sage Publications Ltd. 
Heron, G., \& Murray, R. (2004). The place of writing in social work. Journal of Social Work, 4(2), 199-214. doi: 10.1177/1468017304045410

Hess, P. M., \& Mullen, E. J. (Eds.). (1995). Practitioner-researcher partnerships: Building knowledge from, in, and for practice. Washington, DC: NASW Press.

Hislop, J., Murray, R., \& Newton, M. (2008). Writing for publication: A case study. Practice Development in Health Care, 7(3), 156-163. doi: 10.1002/pdh.262

Hoover, J. F. (2005). Effective small group and team communication. Wadsworth, CA: Thompson.

Houfek, J. F., Kaiser, K. L., Visovsky, C., Barry, T. L., Nelson, A. E., Kaiser, M. M., et al. (2010). Using a writing group to promote faculty scholarship. Nurse Educator, 35(1), 41-45. doi: 10.1097/NNE.0b013e3181c42133

Houston, S. (2001). Beyond social constructionism: Critical realism and social work. British Journal of Social Work, 31(6), 845-861. doi: 10.1093/bjsw/31.6.845

Jackson, D. (2009). Mentored residential writing retreats: A leadership strategy to develop skills and generate outcomes in writing for publication. Nurse Education Today, 29(1), 9-15.

Johnson, D. W., \& Johnson, F. P. (2006). Joining together: Group theory and group skills (9th ed.). Boston: Pearson.

Judd, R. G., \& Sheffield, S. (2010). Hospital social work: Contemporary roles and professional activities. Social Work in Health Care, 49(9), 856-871. doi: 10.1080/00981389.2010.499825

Lannon, S. L. (2007). Leadership skills beyond the bedside: Professional development classes for the staff nurses. The Journal of Continuing Education in Nursing, 30(1), 17-21.

Lee, A., \& Boud, D. (2003). Writing groups, change and academic identity:Research development as local practice. Studies in Higher Education, 28(2), 187-200. doi: 10.1080/0307507032000058109

Luiselli, J. K. (2010). Writing for publication: A performance enhancement guide for the human services professional. Behavior Modification, 34(5), 459-473. doi: $10.1177 / 0145445510383529$

Macduff, N., \& Netting, F. E. (2000). Lessons learned from a practitioner-academician collaboration. Nonprofit and voluntary sector quarterly, 29(1), 46-60. doi: $10.1177 / 0899764000291004$

Malekoff, A. (1999). A practitioner's journey to becoming a writer. Families in Society: The Journal of Contemporary Human Services, 80, 190-194. 
Malekoff, A. (2006). Putting ideas to paper: A guidelines for practitioners (and others) who wish to write for publication. Social Work With Groups, 29(2), 57-72. doi: 10.1300/J009v29n02_05

Marks, D. F. (2002). Perspectives on evidence-based practice. Retrieved 14 May, 2005, 2005, from http://www.hda-online.org.uk/evidence/persp_evid_dmarks.pdf

Marsh, J. C. (2005). Six steps to stronger journal publication in social work. Social Work, 50(1), 4-6.

McCleary, L. (2008). Drawing support from a writing group. Nursing, 38(9), 46-47.

Naiburg, S. (2003). Mentors at the gate: Editors talk about clinical writing for journal publication. Clinical Social Work Journal, 31(3), 295-313.

Nevo, I., \& Slonim-Nevo, V. (2011). The myth of evidence-based practice: Towards evidence-informed practice. British Journal of Social Work, 41(1), 1-22. doi: 10.1093/bjsw/bcq149

Northam, S., Yarbrough, S., Haas, B., \& Duke, G. (2010). Journal editor survey: Information to help authors publish. Nurse Educator, 35(1), 29-36.

Parker, R. (2009). A learning community approach to doctoral education in the social sciences. Teaching in Higher Education, 14(1), 43-54. doi: $10.1080 / 13562510802602533$

Plath, D. (2006). Evidence-based practice: Current issues and future directions. Australian Social Work, 59(1), 56-72. doi: 10.1080/03124070500449788

Powell, J. \& Orme, J. (2011). Increasing the confidence and competence of social work researchers: What works? British Journal of Social Work, 1-20, doi: 10.1093/bjsw/bcr027

Pruet, R. A., Shea, T. P., Zimmerman, J., \& Parish, G. (1991). The beginning development of a model for joint research between a hospital social work department and a school of social work. Social Work in Health Care, 15(3), 63-75.

Rickard, C. M., McGrail, M. R., Jones, R., O'Meara, P., Robinson, A., Burley, M., et al. (2009). Supporting academic publication: Evaluation of a writing course combined with writers' support group. Nurse Education Today, 29(5), 516-521. doi: 10.1016/j.nedt.2008.11.005

Rolfe, G. (2009). Writing-up and writing-as: Rediscovering nursing scholarship. Nurse Education Today, 29(8), 816-820. 
Shatzer, M., Wolf, G. A., Hravnak, M., Haugh, A., Kikutu, J., \& Hoffmann, R. L. (2010). A Curriculum Designed to Decrease Barriers Related to Scholarly Writing by Staff Nurses. Journal of Nursing Administration, 40(9), 392-398.

Shaw, I., \& Lunt, N. (2011). Navigating practitioner research. British Journal of Social Work, 1-18. doi: 10.1093/bjsw/bcr025

Sidell, N. L., Adams, P. J., Barnhart, L. L., Bowman, N. J., Fitzpatrick, V. D., Fulk, M. L., et al. (1996). The challenge of practice based research. Social Work in Health Care, 23(2), 99-111. doi: 10.1300/J010v23n02_06

Silverman, E. (2008). From ideological to competency-based: The rebranding and maintaining of medical social work's identity. Social Work, 53(1), 89-91.

Sridhar, Willett, Castiglioni, Heudebert, Landry, Centor, et al., (2011). Scholarship opportunities for trainees and clinician educators: Learning outcomes from a case report writing workshop. Journal of General Internal Medicine, 24(3):398-401. Doi: 10.1007/s11606-008-0873-9

Staudt, M. M., Dulmus, C., \& Bennett, G. A. (2003). Facilitating writing by practitioners: Survey of practitioners who have published. Social Work 48(1), 75-83.

Steinberg, D. M. (2007). From paper to publication: Passing on some tips. Social Work With Groups, 30(2), 41-55.

Stone, T., Levett-Jones, T., Harris, M., \& Sinclair, P. M. (2010). The genesis of 'the Neophytes': a writing support group for clinical nurses. Nurse Education Today, 30(7), 657-661.

Tariman, J. D. (2009). Mentoring in publication: A lifelong legacy. ONS Connect, 24(1), 812.

Thyer, B. A. (2008). Preparing research articles. New York: Oxford University Press.

van de Luitgaarden, G. M. J. (2009). Evidence-based practice in social work: Lesson from judgment and decision-making theory. British Journal of Social Work, 39(2), 243-260. doi: 10.1111/j.1479-6988.2006.00047.x

Vintzileous, A. M., \& Ananth, C. V. (2010). How to write and publish an original research article. American Journal of Obstetrics and Gynecology, 202(4), e1-e6.

Wachs, J. E., Williamson, G., Moore, P. V., Roy, D., \& Childre, F. (2010). It starts with an idea! AAOHN Journal, 58(5), 177-181. doi: 10.3928/08910162-20100428-05

Williams, L. F., \& Hopps, J. G. (1987). Publication as a practice goal: Enhancing opportunities for social workers. Social Work, 32, 373-376. 
Williams, L. F., \& Hopps, J. G. (1988). On the nature of professional communication: Publication for practitioners. Social Work, 33, 453-459.

Yeager, J., \& Saggese, M. L. (2008). Making your agency outcome informed: A guide to overcoming human resistance to change. Families in Society: The Journal of Contemporary Human Services, 89(1), 9-18. doi: 10.1606/1044-3894.3704

Zayas, L. H., Drake, B., \& Jonson-Reid, M. (2010). Overrating or dismissing the value of evidence-based practice: Consequences for clinical practice. Clinical Social Work Journal. doi: 10.1007/s10615-010-0306-1

Zellars, D. F., Howards, V. M., \& Barcie, M. A. (2008). Faculty mentoring programs: Reenvisioning rather than reinventing the wheel. Review of Educational Research, 78(3), 552-588. doi: 10.3102/0034654308320966 